\title{
Analysis of Feed Speed and Cutting Speed of Korean and Japanese Combines Using a High-Speed Camera
}

\author{
M.H. Lee, B.O. Jin, T.J. Park ${ }^{1}$, C.H. Kim ${ }^{1}$ \\ M. H.Heo ${ }^{2}$ and H.T. Kim ${ }^{*}$ \\ Department of Bio-Industrial Machinery Engineering \\ Gyeongsang National University \\ (Institute of Agriculture and Life Science), Jinju, Korea
}

\begin{abstract}
Cutting performance of 5 row Daedong industry combines cutting knife and 5 row Kuboda combines cutting blade were experimented using paddy straw as the object. Cutting positions were $68 \mathrm{~cm}$ left and right from the centre. Cutting performance was measured at three places. The feed rates were $0.6 \mathrm{~m} / \mathrm{s}, 1.1 \mathrm{~m} / \mathrm{s}, 1.6 \mathrm{~m} / \mathrm{s}$, and the cutting speeds were 600 RPM, 990 RPM, 1,380 RPM. Each of the speed-specific cutting shapes were measured three times and repeated 3 times. Steps of cutting the straw shape, angle and the number of none cutting and biting were quantified by measuring the total of three. The difference between the smallest straw size and the highest straw size was measured. The distance between the highest straw and the lowest straw was calculated to obtain the angle. The number of truncated and broken straw was measured to quantify the cutting shape. The optimum feed rate and the cutting speed of Korean and Japanese combine were identified according to the cut shape, by using a high-speed camera. If the feed rate and cutting speed were increased, number of cutting was lower; thus there was a less load on the cutting blade between the blade and the cutting target, and the cutting shape was not clean. However, when the feed rate and the cutting speed were lower, the cutting shape was clean, but much higher cutting force was exerted and higher power was consumed, which was a burden on the combine.
\end{abstract}

Keywords: Combine, cutting shape, cutting speed, feed speed, rice straw

\section{INTRODUCTION}

With changing domestic agriculture to a large-scale and mechanized one, the use of agricultural machinery and their parts supply is also increasing in Korea. One such machinery tool is the binder or combine cutting knife, which comprises of a cutting blade attached to a knife bar by a rivet to form a triangular shape. The cutting blade is an

\footnotetext{
1 Daedong Industrial Co., Ltd., Chang Nyoung, Korea

2 Woosung Precision Industrial co. Ltd, Jinju, Korea

*. Corresponding author: bioani@gnu.ac.kr
} 
indispensable component of combine and has a lot of usage. However, the cutting blades and also other parts of combine is mostly produced by foreign manufacturing technology and therefore, such parts comprise of half of the agricultural machinery imports (Kim et al., 2006). Thus, domestic manufacturing needs to be developed for the localization of these components. Domestic cutting blades are made of carbon steel (SK5), whose surface is hardened by a high-frequency heat treatment. So, deformation of the knife occurs easily. Deterioration in the cutting performance is also a common problem with the domestic blades. Many farmers, thus, import expensive cutting blades from Japan (Choi and Kim, 2004). Moreover, a number of breaks in the domestic cutting blades perform far behind the Japanese blades. The reason is attributed to the mismatch of the cutting speed and feed ratio in the domestic combines. In this study, attempts have been made to identify the cutting shape depending upon the cutting speed and the feed rate, using a high-speed camera. The differences in the shape of the cutting of both the domestic and foreign combines were also compared.

\section{METHODOLOGY}

An in-house transfer device and the actual combine's cutting device were used in order to identify the cutting shapes. The actual feed rate was combined with the rate of the in-house transfer device that can be adjusted from $0-0.33 \mathrm{~m} / \mathrm{s}$. Three transfer ports were also mounted on the transport device, so that three crops could be cut simultaneously. A highspeed camera was used to identify the shape of the cutting device. After removing all the unwanted parts in order to facilitate the actual combine cutting device, the device was fixed to a fixed frame. Experiment was conducted indoor to facilitate the use of a high-speed camera to monitor. The cutting device was driven by a drive motor and both were connected to each other via a belt pulley. A tachometer was attached via powered links to determine and adjust the cutting speed. Straw was used as the object for cutting. This is because prior research by the same team has proven that the cutting force required for straw was similar to that of matured paddy. Hence straw was used as a substitute. Whether the pattern of the cut crop changed with the change in experimental variables was confirmed by the high-speed camera. After the experiment, the cut shape was measured and expressed quantitatively. Figures 1 to 4 show the design drawings and the pictures of the transfer device and the cutting device. 

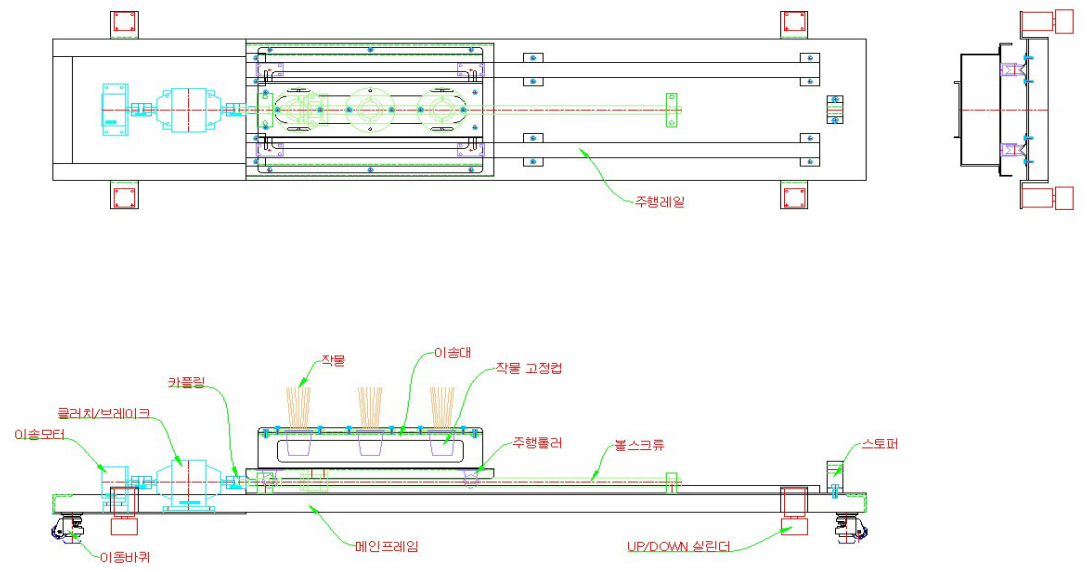

Fig. 1. Design drawings of the transfer device
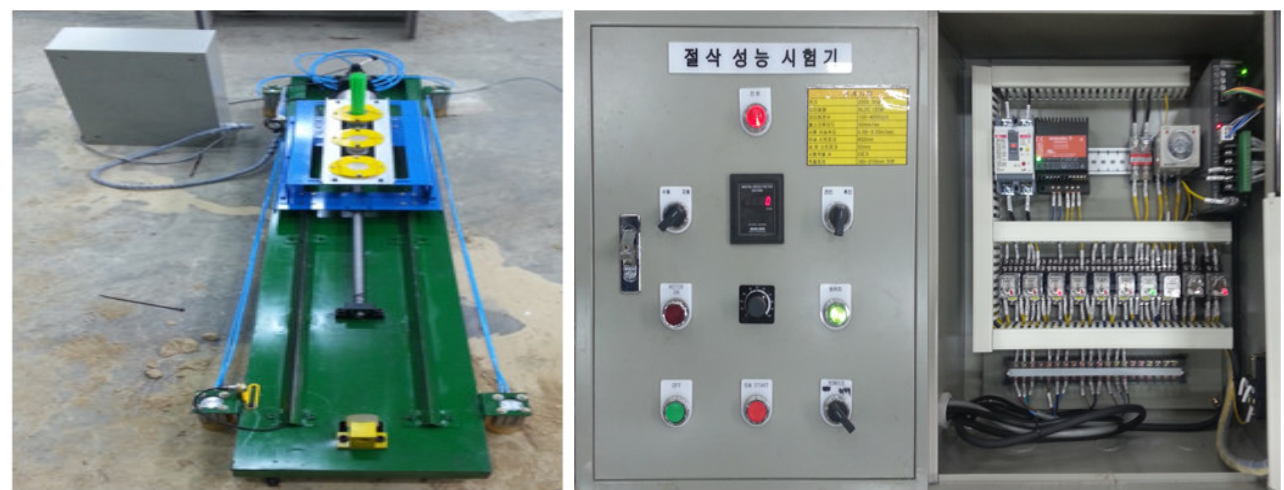

Fig. 2. Picture of a transfer device and controller
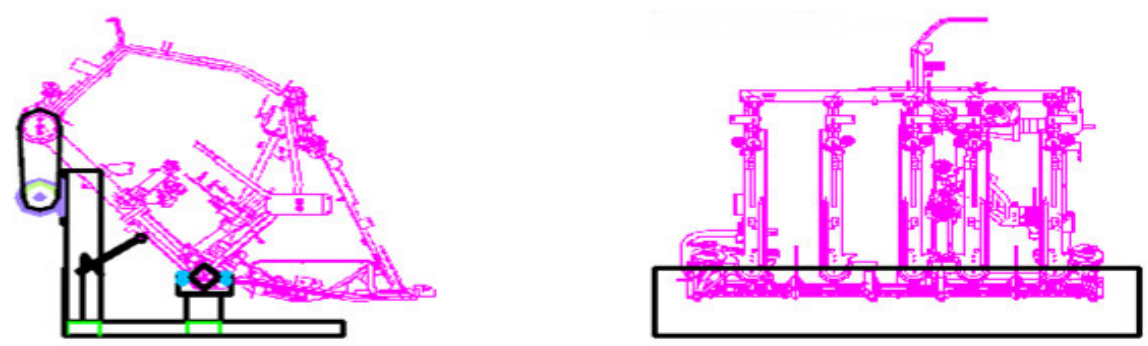

Fig. 3. Design drawings of the cutting device 

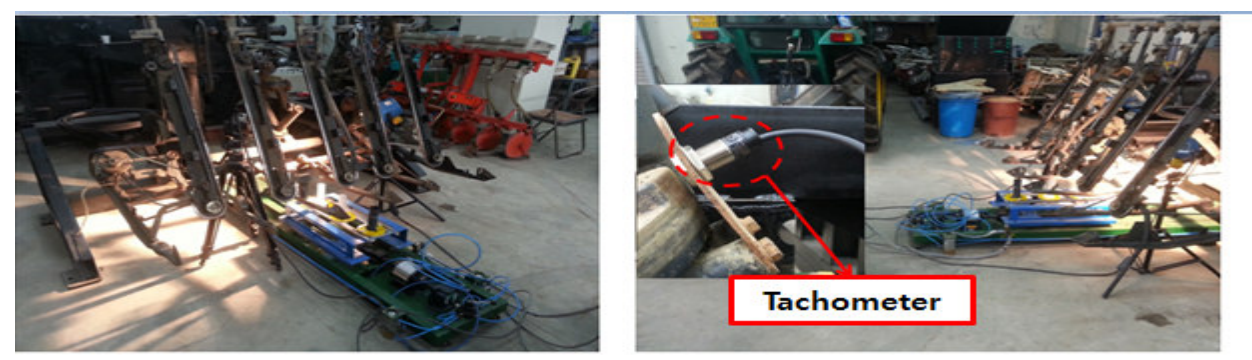

Fig. 4. Experimental setup

Commercially available straw (diameter $0.6 \mathrm{~cm}$ ) was used in the experiment. Five row (5 rows) Daedong industry combine's cutting knife and 5 row Kuboda combine's cutting blade were used in experiment. The cutting performance was measured. The experimental parameters have been listed in Table 1. Cutting position was $68 \mathrm{~cm}$ left and right from the centre (Figure 5). The cutting performance was measured in three different areas. The feed rates were $0.6 \mathrm{~m} / \mathrm{s}, 1.1 \mathrm{~m} / \mathrm{s}, 1.6 \mathrm{~m} / \mathrm{s}$ and the cutting speeds were 600 RPM, 990 RPM, 1380 RPM. For each cutting speed, the cut shapes were measured three times. The shape of the cut straw, cutting angle, the number of straw that were not cut or bit were quantified by measuring the total of three measurements. The difference between the smallest straw size and the highest straw size was measured. As shown in Figure 6, the distance between the highest straw and the lowest straw was calculated to obtain the angle. The number of truncated and broken straw was measured to quantify the cutting shape. Because the average number of stems was measured for 35 paddy, 35 straws were tied with elastic rubber band and fixed to paper cups by paraffin for the experiment.

Table 1. Experimental design

\begin{tabular}{ll}
\hline Division & Korea cutting knife $(\mathrm{kgf})$ \\
\hline Cutting speed & $600,900,1380 \mathrm{rpm}$ \\
Conveying speed & $0.6,1.1,1.6 \mathrm{~m} / \mathrm{sec}$ \\
Experimental location & Cutting knife on the left, right and centre \\
Number of experiment & $3 \times 3 \times 3 \times 3=81 \times 3$ repeat $=243$ \\
Cutting target & Straw \\
\hline
\end{tabular}

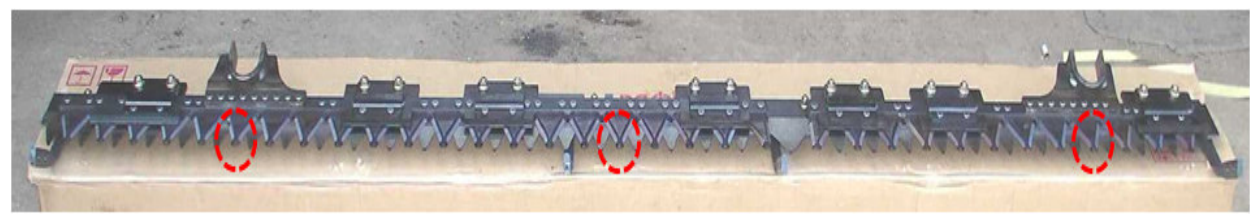

Fig. 5. Experimental points (Left, Centre, Right) 


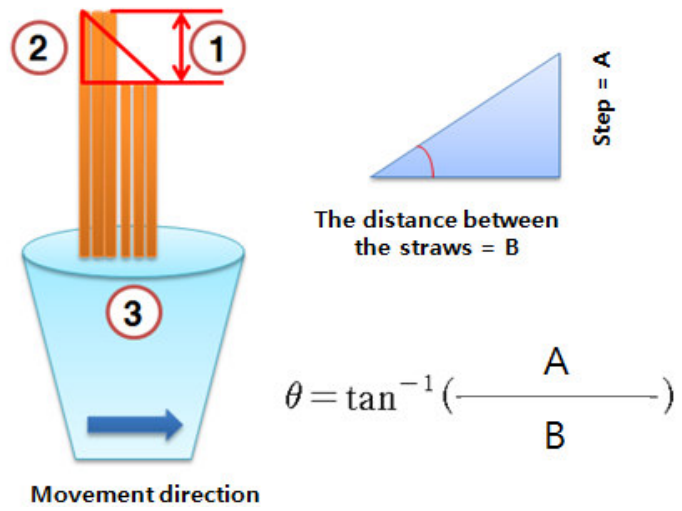

Fig. 6. Methods of quantifying

\section{RESULTS AND DISCUSSION}

In previous experiments, measuring the shape of the paddy during cutting the shape was messy, and the cut shapes were difficult to identify. In order to solve this problem, shape of the cut straw was measured. After cutting the straw, the shapes were not affected by change property of matter. The experimental results showed that majority of the cutting object cut at $1 / 3$ of the blade. If the cutting speed was increased, cutting would occur several times at the beginning of the blade. If the feed rate was increased, the object was held up to the middle of the blade, but the cutting shape was not clean. After more experiments, analysis of none cutting and biting phenomenon was determined and a correlation between feed rate and cutting speed was established. According to the running speed of a combine optimum cutting speed was judged.

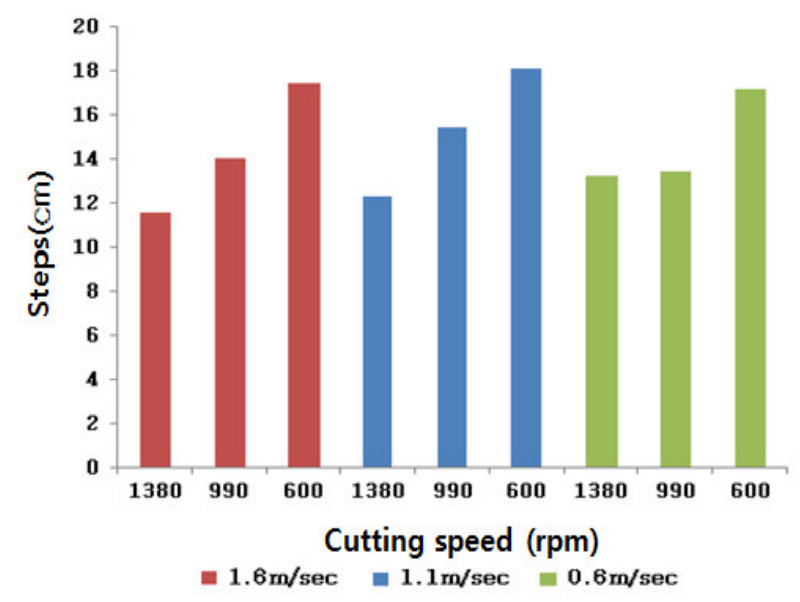

Fig. 7. Variation of steps with cutting speed (Daedong Ltd.) 
Figure 7 shows that as the cutting speed became lower, the size of the steps increased. The steps did not change significantly with the feed rate as they were affected by the cutting speed. However, when the feed rate and the cutting speed were lower, the cutting shape was clean, but much higher cutting force was exerted and higher power was consumed, which was a burden on the combine.

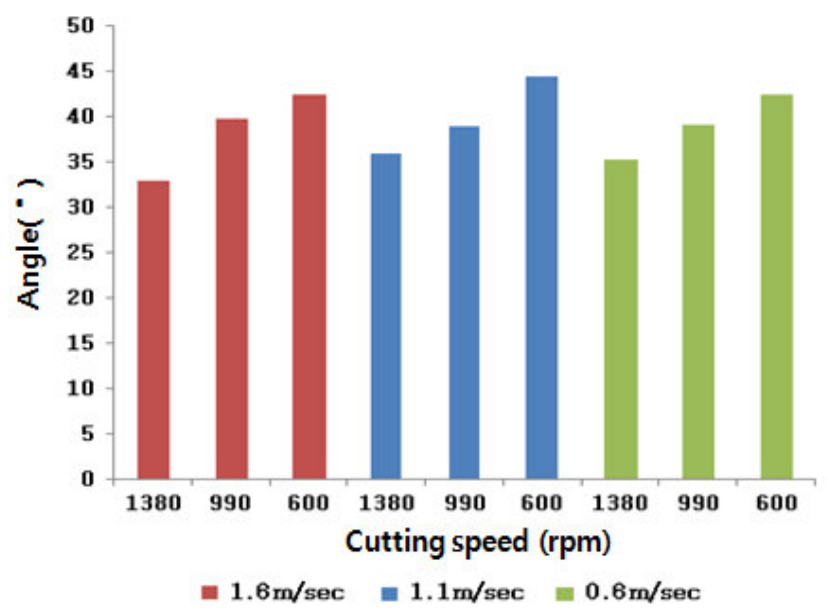

Fig. 8. Variation of angle with the cutting speed (Daedong Ltd.)

Figure 8 shows that as the cutting speed decreased, the angle became larger. This behaviour was similar to that of the variations in steps. The cutting target was cut multiple times as the angle increased.

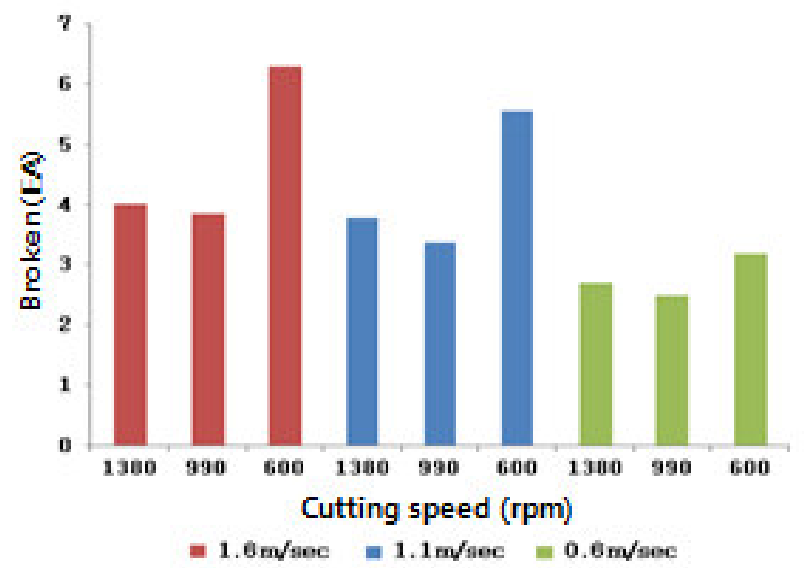

Fig. 9. Variation of the number of broken straw with the cutting speed (Daedong Ltd.)

Figure 9 shows the number of breaks with cutting speed for Daedong industrial 5 row combine. The graph shows that lower the cutting speed was, fewer were the number of 
breaks. The maximum breaks were found at $600 \mathrm{rpm}$. When the cutting speed was reduced, the cutting blade was in more contact with the cutting target, thereby showing a tendency to cut more. If the cutting speed was reduced below a certain limit, the cutting speed and the feed rate became a mismatch and the number of broken straw increased. If the feed rate was lower, the number of broken straw seemed to decrease slightly.

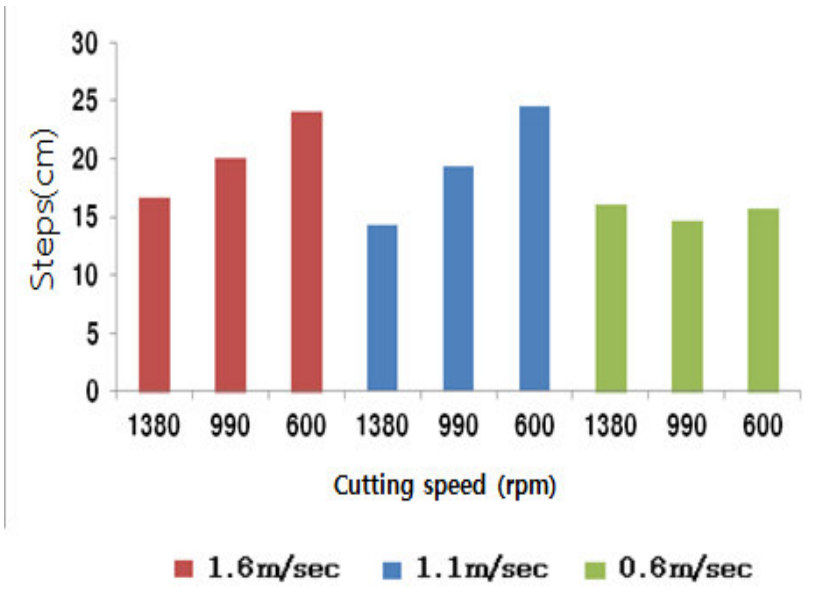

Fig. 10. Variation of steps with the cutting speed (Kubota)

Figure 10 shows the step with cutting speed for 5 row Kubota combine. The transfer speeds were 1.6, 1.1 and $0.6 \mathrm{~m} / \mathrm{s}$. It can be seen that the steps increased if the cutting speed was reduced. However, at feed rate $0.6 \mathrm{~m} / \mathrm{s}$, lowest step was obtained at $990 \mathrm{rpm}$. It appeared that the most appropriate cutting speed and the feed speed were $990 \mathrm{rpm}$ and $0.6 \mathrm{~m} / \mathrm{s}$, respectively. For the case of $1.6 \mathrm{~m} / \mathrm{s}$ and $1.1 \mathrm{~m} / \mathrm{s}$, appropriate cutting speed will be investigated in future to obtain the lowest step.

Figure 11 shows variations in cutting angle with the cutting speed of Kubota 5 row combine. The behaviour of the angle of cutting or the cutting angle looked similar to the step's graph pattern. When the transfer rate was $1.6 \mathrm{~m} / \mathrm{s}$ and $1.1 \mathrm{~m} / \mathrm{s}$, it can be seen that the cutting angle increased as the cutting speed became lower. At feed rate $0.6 \mathrm{~m} / \mathrm{s}$, the lowest cutting angle was obtained at $990 \mathrm{rpm}$. Thus, the most appropriate cutting speed and the feed speed were $990 \mathrm{rpm}$ and $0.6 \mathrm{~m} / \mathrm{s}$, respectively. For the case of $1.6 \mathrm{~m} / \mathrm{s}$ and $1.1 \mathrm{~m} / \mathrm{s}$, appropriate cutting speed will be investigated in future to obtain the lowest cutting angle.

Figure 12 shows variation of the number of breaks with Kubota 5 row combine's cutting speed, which is similar to the cutting angle and step graph, when the transfer rate was $1.6 \mathrm{~m} / \mathrm{s}$ and $1.1 \mathrm{~m} / \mathrm{s}$, it can be seen that lower the cutting speed higher was the number of broken straw. At the feed rate of $0.6 \mathrm{~m} / \mathrm{s}$ lowest break was obtained at $990 \mathrm{rpm}$. Therefore, the most appropriate cutting speed and the feed speed were $990 \mathrm{rpm}$ and $0.6 \mathrm{~m} / \mathrm{s}$, respectively. 


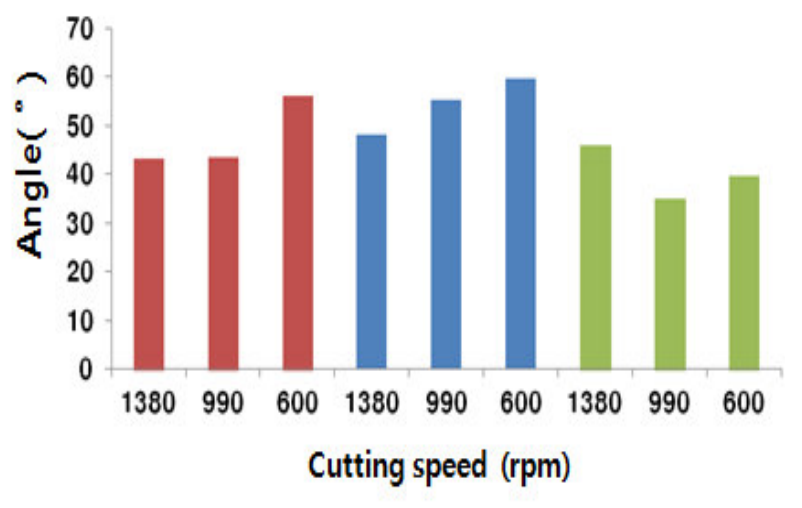

$\square 1.6 \mathrm{~m} / \mathrm{sec} \quad 1.1 \mathrm{~m} / \mathrm{sec} \equiv 0.6 \mathrm{~m} / \mathrm{sec}$

Fig. 11. Variation of angle with the cutting speed (Kubota)

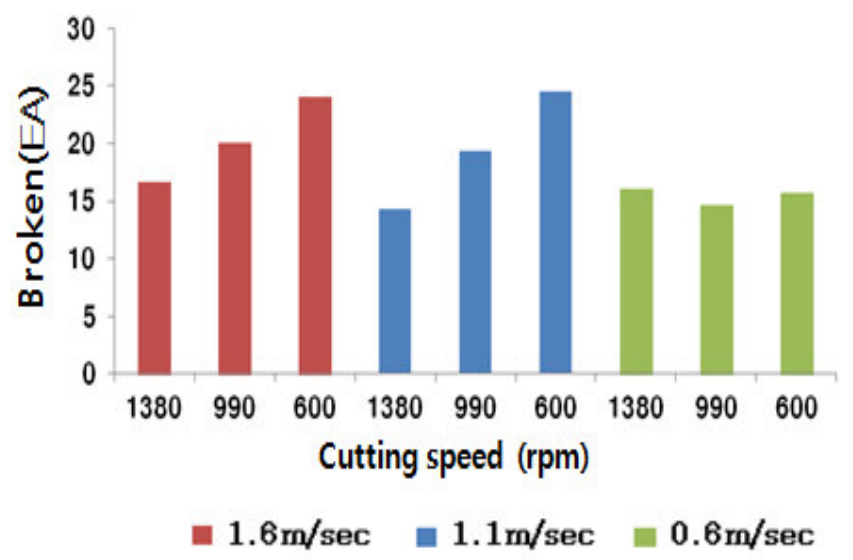

Fig. 12. Variation of the number of broken straw with the cutting speed, (Kubota)

\section{CONCLUSIONS}

In this study, the feed rate and the cutting speed of Korean and Japanese combine were identified according to the cut shape by using a high-speed camera. If the feed rate and cutting speed was increased, number of cutting was lower; thus there was less load on the cutting blade between the blade and the cutting target, and the cutting shape was not clean. However, when the feed rate and the cutting speed were lower, the cutting shape was clean, but much higher cutting force was exerted and a higher power was consumed, which was a burden on the combine. Reinvestigation on the level difference, broken and cut angle would definitely help to find the optimum cutting speed via setting different values of the feed rate and the cutting speed. 


\section{ACKNOWLEDGEMENT}

This work was supported by the Centre for IT Convergence Agricultural Machinery (ITAM) grant (NO. R14-1) funded by the Ministry of Trade, Industry and Energy, Korea.

\section{REFERENCES}

Choi, W.Y. and Kim, T.H. (2004). An effect of the shape of cutting blaed on cutting resistance of rice stalk. Agricultural research bulletin of Kyungpook Univ., 22, 41 - 48.

Kim J.H., Choi, C.H., Kim, Y.J., Nam, E.H. and Mun, J.H. (2006). Development of Measurement System for Combine Header Diagnoses. Journal of Biosystems Engineering, 11(1), $98-103$. 